\title{
Effect of Apical Patency on Postoperative Pain after Single-visit Endodontic Treatment in Necrotic Teeth with Asymptomatic Apical Periodontitis: A Randomised Control Trial
}

\author{
Ajmal Yousaf, Fatima Ali, Faisal Bhangar and Mafaza Alam \\ Department of Operative Dentistry, Armed Forces Institute of Dentistry, Rawalpindi, Pakistan
}

\begin{abstract}
Objective: To find out the effect of apical patency on postoperative pain after single-visit endodontic treatment in necrotic teeth with asymptomatic apical periodontitis.

Study Design: Single blind randomised clinical trial.

Place and Duration of Study: Department of Operative Dentistry, Armed Forces Institute of Dentistry, Rawalpindi, Pakistan, from June to December 2020.

Methodology: A total of 240 patients with good general health presenting with asymptomatic apical periodontitis in their mandibular first molar teeth were selected and randomly divided into two equal groups with the help of scientific number table. Endodontic therapy was initiated and root canals were prepared with ProTaper Next system. In the Patency group, a size $10 \mathrm{~K}$ file was used as patency file and carried $01 \mathrm{~mm}$ beyond working length between successive files. In the non-patency group, the file was carried till the working length. Obturation was done with cold lateral condensation using Pro Taper Next GP points, and permanent restoration was done with composite. The patients were informed to record pain scores after 24 and 48 hours and bring the VAS after one week. The data was analysed using SPSS version 22.

Results: There were 137 (57.08\%) female and 103 (42.92\%) male patients; 78 (65\%) of patients in Patency group and 67 $(55.83 \%)$ in Non-patency group, had no pain after 24 hours $(p=0.345)$. In Patency group, $101(84.17 \%)$ patients had no pain after 48 hours as compared to $98(81.67 \%)$ patients of Non-patency group $(p=0.649)$. So apical patency reduced pain, but not in statistically significant proportion.

Conclusion: Maintaining apical patency in necrosed teeth with asymptomatic apical periodontitis does not significantly reduce postoperative pain after single visit endodontic treatment.
\end{abstract}

Key Words: Apical patency, Postoperative pain, Asymptomatic apical periodontitis.

How to cite this article: Yousaf A, Ali F, Bhangar F, Alam M. Effect of Apical Patency on Postoperative Pain after Single-visit Endodontic Treatment in Necrotic Teeth with Asymptomatic Apical Periodontitis: A Randomised Control Trial. J Coll Physicians Surg Pak 2021; 31(10):1154-1158.

\section{INTRODUCTION}

Postoperative pain is a frequent complication during and after endodontic treatment; and has been estimated to be between $3-58 \%{ }^{1}$ In necrotic teeth with asymptomatic apical periodontitis, there is a local balance between the microbial flora and the host defense mechanisms. ${ }^{2}$

Correspondence to: Dr. Ajmal Yousaf, Department of Operative Dentistry, Armed Forces Institute of Dentistry, Rawalpindi, Pakistan

E-mail: bangashajmal@gmail.com

Received: January 05, 2021; Revised: August 29, 2021;

Accepted: September 17, 2021

DOI: https://doi.org/10.29271/jcpsp.2021.10.1154
During canal preparation, various irritants like dentinal debris, necrotic pulp remnants, medicaments and irrigating solutions can gain access to the peri-apical tissues disturbing this balance to cause peri-apical inflammation and pain. ${ }^{1,2}$ The incidence of postoperative pain is low in patients with a vital pulp without any peri-radicular pathosis; and is highest in patients who present with severe preoperative pain and swelling, particularly with a necrotic pulp and peri-radicular pathosis. Thus any procedure in close proximity to the peri-apical tissues has a potential to cause postoperative pain. ${ }^{3}$

Instrumentation in apical third part of the root canal system can lead to iatrogenic mishaps including blockage either due to dental hard and soft tissue debris or pulpal remnants, transportations, ledges and perforations. ${ }^{4}$ Adequate debridement of therootcanals, especially the apical third portion, is quiteessential for the long term success of a root canal treated tooth. ${ }^{5}$ 
However, complete debridement of the apical portions presents challenges because of its complex and unpredictable anatomy; and to overcome this problem, maintaining apical patency has been suggested in the literature. ${ }^{5}$

The American Association of Endodontists has defined apical patency as a technique in which the apical portion of the root canal is maintained free of debris by recapitulation, using a small size file through the apical foramen. ${ }^{6}$ Maintaining apical patency has the advantage of preventing accumulation of debris in the apical third with the decreased possibility of procedural accidents, like ledges and perforations; which increases the success of endodontic treatment. ${ }^{7,8}$ In addition, helping to maintain the working length throughout the procedure, it improves tactile sensation, and facilitates irrigation in the apical third of the root canal system. ${ }^{8,9}$

However, the use of this technique is quite controversial owing to the risk of extrusion of debris and irrigating solutions resulting in inflammation of the peri-apical tissues as shown by Adham et al. ${ }^{10}$ However, study by Snigdha et al. ${ }^{11}$ reported significantly less postoperative pain when apical patency was maintained in teeth with necrotic pulps. A study by Arora et al. showed that apical Patency group had significant less pain (34\%) as compared to Non-patency group ( $52 \%, p=0.163 .{ }^{12}$

The aim of this study was to compare the incidence of postoperative pain with and without apical patency after 24 and 48 hours with single-visit endodontic treatment with necrotic pulp and asymptomatic apical periodontitis.

\section{METHODOLOGY}

After taking approval from the Ethical Committee of this Institution, a prospective randomised clinical study was planned at Operative Department from 01 June 2020 to 31 December 2020. This trial was registered on clinical trials database of U.S. National Library of Medicine with registration \# NCT04551209. After taking informed consent, 240 patients of 20-50 years of age from both genders with good general, mental and physical health, were selected for this study.

The sample size was calculated by using the Clin Calc calculator. With a level of significance $5 \%$, with power of test kept at $80 \%$, a total sample size of 236 patients was calculated, which was increased to 240 , with 120 patients in each of the two groups without any lost-to-follow-up, based on the population proportion $A=34 \%$ and population proportion $B=52 \%$. ${ }^{12}$

The first mandibular molar teeth with asymptomatic apical periodontitis with necrotic pulps, without any intra-oral or extra-oral swelling or any draining sinus tract, were selected for this study. Patients on preoperative analgesics and antibiotics, immune-comprised patients, pregnant and lactating mothers were all excluded from this study.

The patients reporting to the Department of Operative Dentistry, who were advised endodontic treatment of their mandibular first molar, were screened for inclusion by taking history, performing relevant clinical examination and necessary investigations along with peri-apical radiographs. The whole procedure of the study was explained to the patients in Urdu. After taking written informed consent from the willing participants of this study, the procedure wasstarted.

Two groups were formed by simple randomisation with the help of scientific number table into group A (Patency group) and Group B (Non-patency group).

Root canal treatment was initiated under local anesthesia (lignocain septodont). Working length was obtained with Root ZX II J MORITA apex locator and confirmed with a radiograph. The root canals were instrumented with Dentsply ProTaper Next system under copious irrigation with $5.25 \%$ sodium hypochlorite $(\mathrm{NaOCl})$ (Parcan Septodont) and 17\% EDTA solution (PDSwiss).

In Patency group, a size $10 \mathrm{~K}$ file (MANI Japan) was passed beyond the apical foramen between each instrument change to maintain apical patency, while in Non-patency group, Kfile was carried up to the working length only. A final peri-apical radiograph was taken in the patency group with the $10 \mathrm{~K}$ patency file $01 \mathrm{~mm}$ beyond the apical foramen to confirm patency.

Obturation was done with cold lateral condensation using Dentsply Pro Taper Next GP points and permanent restoration was done with Spectrum Dental Composite Dentsply. At the end of this appointment, patients were given a visual analogue scale (VAS), and were advised to mark at the scale according to his pain intensity after 24 hours and 48 hours, and were asked to bring these readings with them on the next scheduled visit after one week for tooth preparation for definitive indirect restorations. VAS scores of less than 4 were considered as no pain, score between 4-7 were considered as mild and/or moderate pain, and scores of 8 and above were considered as severe pain. (no pain $=<3$, moderate pain $=>4$ to 7 , severe pain $=>8$ ). The data was analysed using SPSS version 22 . Frequencies and percentages were calculated for categorical variables like gender, age-groups and inter-appointment pain. Chi-square test was used to compare the frequency of pain between the two groups after 24 and 48 hours of endodontic treatment. The pvalue of $<0.05$ was considered significant.

\section{RESULTS}

Total sample was 240 patients having necrotic mandibular first molar teeth with asymptomatic apical periodontitis on single side. Out of total sample, $103(42.92 \%)$ were males, out of which 55 (45.83\%) were in Patency group and $48(40 \%)$ in Non-patency group; $137(57.08 \%)$ were females, out of which 65 (54.17\%) were in Patency group and $72(60 \%)$ in Non-patency group. Majority of the patients were in age group range of 20-40 years. Gender was found to have no significant association with the incidence of postoperative pain. The $p$ values after 24 hours for male gender and female gender were 0.142 and 0.650 ; and after 48 hours it were 0.144 and 0.470 , respectively. Gender and age distribution were calculated, and data is presented in Table I. In Patency group after 24 hours, 78 (65\%) of patients had no pain; while in Non-patency group, 67 (55.83\%) had no pain with $p=0.345$. Patency group patients had less pain after 48 hours as well ( $p=0.649$, Table II). 
Table I: Gender and age distribution and frequency in Patency group \& Non-patency group.

\begin{tabular}{|l|l|c|c|c|c|}
\hline \multirow{2}{*}{ Variables } & \multicolumn{2}{|c|}{ Patency group (n=120) } & \multicolumn{2}{c|}{ Non patency group (n=120) } \\
\cline { 2 - 6 } & Frequency(n) & Percentages (\%) & Frequency (n) & Percentages (\%) \\
\hline \multirow{3}{*}{ Gender } & Male $(n=103)$ & 55 & $45.83 \%$ & 48 & $40 \%$ \\
\cline { 2 - 6 } & Female $(n=137)$ & 65 & $54.17 \%$ & 53 & $60 \%$ \\
\hline \multirow{3}{*}{ Age } & $20-30$ & 50 & $41.67 \%$ & 60 & 44.17 \\
\cline { 2 - 6 } & $31-40$ & 51 & $42.5 \%$ & $50 \%$ & 7 \\
\cline { 2 - 6 } & $41-50$ & 19 & $15.83 \%$ & $5.83 \%$ & \\
\hline
\end{tabular}

\begin{tabular}{|c|c|c|c|c|c|c|c|c|}
\hline \multirow[t]{2}{*}{ Post op hours } & \multirow[t]{2}{*}{ Gender } & \multirow[t]{2}{*}{ Groups } & \multicolumn{4}{|c|}{$\begin{array}{c}\text { Pain severity } \\
\text { n (\%) }\end{array}$} & \multirow[t]{2}{*}{ Total } & \multirow[t]{2}{*}{ p-value* } \\
\hline & & & No pain & Mild & ain & Severe pain & & \\
\hline \multirow{4}{*}{24 hours } & \multirow{2}{*}{ Male } & Patency & 35 (33.98\%) & $16(15$ & $53 \%)$ & $4(3.88 \%)$ & $55(53.40 \%)$ & \multirow{2}{*}{0.14} \\
\hline & & Non Patency & $22(21.36 \%)$ & $23(22$ & $33 \%)$ & $3(2.91 \%)$ & $48(46.60 \%)$ & \\
\hline & \multirow{2}{*}{ Female } & Patency & $43(31.39 \%)$ & $17(12$ & $41 \%)$ & $5(3.65 \%)$ & $65(47.45 \%)$ & \multirow{2}{*}{0.65} \\
\hline & & Non Patency & $45(32.85 \%)$ & $18(13$ & $14 \%)$ & $9(6.56 \%)$ & $72(52.55 \%)$ & \\
\hline \multirow{4}{*}{48 hours } & \multirow{2}{*}{ Male } & Patency group & $48(44.86 \%)$ & $6(5$. & $1 \%)$ & $1(0.93 \%)$ & $55(51.40 \%)$ & \multirow{2}{*}{0.14} \\
\hline & & Non patency & $38(35.51 \%)$ & $10(9$ & $5 \%)$ & $4(3.74 \%)$ & $52(48.60 \%)$ & \\
\hline & \multirow{2}{*}{ Female } & Patency & $53(39.85 \%)$ & $9(6$. & $7 \%)$ & $3(2.25 \%)$ & $65(48.87 \%)$ & \multirow{2}{*}{0.47} \\
\hline & & Non patency & $60(45.11 \%)$ & $5(3$. & $6 \%)$ & $3(2.25 \%)$ & $68(51.13 \%)$ & \\
\hline \multicolumn{9}{|c|}{ Incidence of pain in Patency group \& Non-patency group after 24 hours and 48 hours. } \\
\hline \multicolumn{2}{|l|}{ Post op hours } & Pain & \multicolumn{2}{|c|}{$\begin{array}{l}\text { Patency group } \\
(n=120)\end{array}$} & \multicolumn{2}{|c|}{$\begin{array}{c}\text { Non patency group } \\
(\mathrm{n}=120)\end{array}$} & \multicolumn{2}{|c|}{ p-value* } \\
\hline \multirow{3}{*}{24 hours } & & No pain & \multicolumn{2}{|c|}{$78(65 \%)$} & \multicolumn{2}{|c|}{$67(55.83 \%)$} & \multirow{3}{*}{\multicolumn{2}{|c|}{0.345}} \\
\hline & & Mild pain & $33(27.5$ & $\%)$ & & $1(34.17 \%)$ & & \\
\hline & & Severe pain & $9\left(7.5^{c}\right.$ & & & $12(10 \%)$ & & \\
\hline \multirow{3}{*}{48 ho48 hours } & & No pain & $101(84$. & $17 \%)$ & & $8(81.67 \%)$ & \multirow{3}{*}{\multicolumn{2}{|c|}{0.649}} \\
\hline & & Mild pain & $15(12.5$ & $\%)$ & & $15(12.5 \%)$ & & \\
\hline & & Severe pain & $4(3.33$ & & & $7(5.83 \%)$ & & \\
\hline
\end{tabular}

\section{DISCUSSION}

The idea of apical patency was first advocated by Buchanan, describing a patency file as a small K-file, which would passively move through the minor apical diameter and beyond the apical foramen without widening it. ${ }^{13}$ Over the years, numerous authors have advocated the use of a patency file because it causes less apical leakage, prevents bacterial inoculation of peri-apical tissues, and improves debridement and irrigation of the apical third of the root canal system, thus reducing the chances of postoperative pain. ${ }^{14,15}$ There have also been conflicting studies on the use of a patency file. Tinaz et al. reported greater extrusion of irrigant solution into the peri-apical tissues; ${ }^{16}$ Goldberg et al. reported transportation of apical third of the canal with maintaining apical patency. ${ }^{17}$

In the present study, postoperative pain in teeth with necrotic pulp with and without apical patency was compared. Both groups showed a reduction in pain over the 24 hours period after endodontic treatment. In the Patency group after 24 hours, $65 \%$ of patients had no pain; while in Non-patency group, $55.83 \%$ had no pain. Patency group patients had less pain after 48 hours as well. Although the patients in the patency group had comparatively less pain, the results were found to be statistically insignificant. A similar study by Arslan et al. compared incidence of postoperative pain with apical patency in teeth with apical periodontitis having necrosed pulps; ${ }^{18}$ they also concluded that although apical patency did reduce pain more than the control group and there was less incidence of flare-up, but the results were not statistically significant. Another study compared postoperative pain; while maintaining apical patency in teeth with necrotic pulp and asymptomatic apical periodontitis also concluded that pain was significantly less in the Patency group compared to the Non-patency group during the first five days, after which the results were insignificant. ${ }^{19}$ Likewise, other studies also concluded that maintaining apical patency reduced the incidence of flare-up. ${ }^{20-22}$

A study by Ahmed et al. on the effect of apical patency on postoperative pain concluded that apical patency significantly decreases postoperative pain in teeth with necrotic pulp and apical periodontitis. ${ }^{23}$ This is similar to the present study in which the authors found no statistically significant differences in postoperative pain reduction between the Patency and Non-patency group. The less incidence of pain in the Patency group can be attributed to the fact that maintaining apical patency helps in clearing bacterial and pulpal debris in the apical third along with improving irrigation which leads to less peri-apical inflammation and subsequently reduced pain. ${ }^{15}$ 
Analysing a single variable as a factor responsible for postoperative pain is difficult as pain is a subjective phenomenon and is influenced by multiple factors. It is influenced by psychological, emotional, cultural and social behaviors. Different individuals respond differently to varying degrees of pain depending on their threshold for it. The preoperative pain also influences postoperative pain in endodontics. ${ }^{24}$ Pain can also be strongly influenced by the element of fear. The dental treatment is often a fear and anxiety provoking event for many patients that could influence their current treatment outcome and response to that treatment in the future. ${ }^{25}$

It is also important to point out that the present study included mandibular first molars with necrotic pulp and asymptomatic apical periodontitis only; and due to the specific nature of the tooth, the results of this study cannot be generalised to teeth with vital pulps without apical periodontitis. Sample size should also be increased for future studies on the topic. The overall success of apical patency on the success of root canal treatment could form a basis for future studies.

This was a single blind randomised control trial, thus it would have been better if we had done double blinding. But as in this trial, a single operator was doing the whole clinical procedure so it was not possible for him to do double blinding. Preoperative pain was not calculated. The effect of this on the present results is, therefore, unknown.

\section{CONCLUSION}

Maintaining apical patency in necrosed asymptomatic apical periodontitis teeth does not significantly reduce postoperative pain after single-visit endodontic treatment.

\section{DISCLOSURE:}

The article is original and not presented anywhere else.

\section{FUNDING:}

All patients were entitled for free treatment.

\section{ETHICAL APPROVAL:}

Ethical approval was taken from Institutional Review Board of Armed Forces Institute of Dentistry, $\mathrm{CMH}$, Rawalpindi prior to the initiation of study. (AFID No. 905/Trg-ABP1K2, dated 26 May 2020).

\section{PATIENTS' CONSENT:}

Informed consents were taken from all patients before writing the article.

\section{CONFLICT OF INTEREST:}

The authors declared no conflict of interest.

\section{AUTHORS' CONTRIBUTION:}

AY: Supervised the study, helped in manuscript writing, finalised the study.

FA: Literature review, data collection and results.
FB: Reference citation and proofreading of the article.

MA: Data collection and manuscript writing.

\section{REFERENCES}

1. Konark, Singh A, Kumar A, Nazeer J, Singh R, Singh S. Incidence of postoperative flare-ups after single-visit and multiple-visit endodontic therapy in permanent teeth. J Indian Soc Pedod Prev Dent 2020; 38(1):79-83. doi: 10.4103/JISPPD.JISPPD_354_19.

2. Nair M, Rahul J, Devadathan A, Mathew J. Incidence of endodontic flare-ups and its related factors: A retrospective study. J Int Soc Prev Community Dent 2017; 7(4):175-9. doi: 10.4103/jispcd.JISPCD_61_17.

3. AlRahabi MK. Predictors, prevention, and management of postoperative pain associated with nonsurgical root canal treatment: A systematic review. J Taibah Univ Med Sci 2017; 12(5):376-84. doi: 10.1016/j.jtumed.2017.03.004.

4. Jafarzadeh H, Mohammadi Z, Shalavi S, Kinoshita J. Establishing apical patency: To be or not to be? J Contemp Dent 2017; 18(4):326-9. doi: 10.5005/jp-journals-10024-2040.

5. Manker A, Solanki M, Tripathi A, Jain M. Biomechanical preparation in primary molars using manual and three NiTi instruments: A cone-beam-computed tomographic in vitro study. Eur Arch Paediatr Dent 2019; 21(2):203-13. doi: 10.1007/s40368-019-00474-0.

6. American Association of Endodontists. Glossary of endodontic terms. 7th ed. Chicago: American Association of Endodontists; 2003.

7. Garg N, Sharma S, Chhabra A, Dogra A, Bhatia R, Thakur S. Clinical evaluation of maintenance of apical patency in postendodontic pain: An in vivo study. Endodontol 2017; 29(2):115.

8. Machado R, Ferrari $\mathrm{CH}$, Back E, Comparin D, Tomazinho LF, Vansan LP. The impact of apical patency in the success of endodontic treatment of necrotic teeth with apical periodontitis: a brief review. Iran Endod J 2016; 11(1):63-6. doi: 10.7508/iej.2016.01.012.

9. Mounce R. Achieving and maintaining apical patency in endodontics: Optimising canal shaping procedures. Gen Dent 2015; 63(1):14-5.

10. Azim AA, Azim KA, Abbott PV. Prevalence of inter-appointment endodontic flare-ups and host-related factors. Clin Oral Investig 2017; 21(3):889-94. doi: 10.1007/s00784016-1839-7.

11. Shubham S, Nepal M, Mishra R, Dutta K. Influence of maintaining apical patency in post-endodontic pain. BMC Oral Health 2021; 21(1):1-0. doi: 10.1186/s12903-021-01632-x.

12. Arora M, Sangwan $P$, Tewari $S$, Duhan J. Effect of maintaining apical patency on endodontic pain in posterior teeth with pulp necrosis and apical periodontitis: A randomised controlled trial. Int Endod J 2016; 49(4):317-24. doi: 10.1111/iej.12457.

13. Iandolo A, Amato A, Martina S, Abdel latif D, Pantaleo G. Management of severe curvatures in root canal treatment with the new generation of rotating files using a safe and predictable protocol. 2021; 14:421-5.

14. Monsef M, Hamedzadeh K, Soluti A. Effect of apical patency 
on the apical seal of obturated canals. J Endod 1997; 23(4):253.

15. Vera J, Arias A, Romero M. Effect of maintaining apical patency on irrigant penetration into the apical third of root canals when using passive ultrasonic irrigation: An in vivo study. J Endod 2011; 37(9):1276-8. doi: 10.1016/j.joen. 2011.05.042.

16. Tinaz AC, Alacam T, Uzun O, Maden M, Kayaoglu G. The effect of disruption of apical constriction on periapical extrusion. J Endod 2005; 31(7):533-5. doi: 10.1097/01.don. 0000152294.35507 .35$.

17. Goldberg F, Masson E. Patency file and apical transportation: An in vitro study. J Endod 2002; 28(7):510-1. doi: 10.1097/00004770-200207000-00005.

18. Arslan H, Yıldız ED, Topçuoğlu HS, Tepecik E, Ayaz N. Success of maintaining apical patency in teeth with periapical lesion: A randomised clinical study. Quintessence Int 2019; 50(9):686-93. doi: 10.3290/j.qi.a43047.

19. Yaylali I, Kurnaz S, Tunca Y. Maintaining apical patency does not increase postoperative pain in molars with necrotic pulp and apical periodontitis: A randomised controlled trial. J Endod 2018; 44(3):335-40. doi: 10.1016/j.joen.2017. 11.013 .
20. Garg N, Sharma S, Chhabra A, Dogra A, Bhatia R, Thakur S. Clinical evaluation of maintenance of apical patency in postendodontic pain: An in vivo study. Endodontol 2017; 29(2):115-9.

21. Sharaan ME, Aboul-Enein NM. Relationship between postpreparation pain and apical patency: a randomized clinical trial. Gulf Med J 2012; 1(1):96-101.

22. Abdulrab S, Rodrigues J, Al-maweri S, Halboub E, Alqutaibi A, Alhadainy $\mathrm{H}$. Effect of apical patency on postoperative pain: A meta-analysis. J Endod 2018; 44(10):1467-73. doi: 10.1016/j.joen.2018.07.011.

23. Ahmed MR, Shahzad R, Sandhu IN. Effects of maintaining apical patency on post-operative pain in molars with necrotic pulp and apical periodontitis. Ann Punjab Med Coll 2018; 12(1):59-61. doi.org/10.29054/apmc/2018.163.

24. Izu KH, Thomas SJ, Zhang P, Izu AE, Michalek S. Effectiveness of sodium hypochlorite in preventing inoculation of periapical tissues with contaminated patency files. J Endod 2004; 30(2): 92-4. doi: 10.1097/00004770-20040200000007.

25. Lin CS, Wu SY, Yi CA. Association between anxiety and pain in dental treatment: A systematic review and meta-analysis. J Dent Res 2017; 96(2):153-62. doi: 10.1177/00220345 16678168. 